\title{
Morphology as syntax, features as categories, functional cascades
}

\author{
M. Rita Manzini \\ University of Florence \\ mariarita.manzini@unifi.it
}

How to cite: Manzini, M. Rita. 2021. Morphology as syntax, features as categories, functional cascades. Isogloss. Open Journal of Romance Linguistics 7,18: $1-8$.

While the call from the editor was interesting and worth following up, it is evident that commenting on a spoken presentation (Michal Starke, NELS talk, November 2020 - henceforth Starke) presents additional risks of misunderstanding or inaccuracy. I will mostly keep to general issues on which I have already written, namely those in the title.

It seems to me that in talking or writing on the generative analysis of morphological phenomena, it is useful to make reference to the research tradition on which the whole enterprise rests. It is potentially misleading to present the field as progressing from Jespersen's (1924) dictum "No one ever dreamed of a universal morphology" to the author's positions. At least one key passage stands in between, namely the work of Morris Halle, who is responsible for establishing generative morphology as a computational model whose units are morphemes and whose basic operation is (morphological) merge. Because this is now the dominant model in the generative field, it is easy to forget that it represents a far from foregone result (see Blevins 2006 for a review, from a contrary position).

Problems with the implementation of this model in the form of Distributed Morphology (DM, Halle and Marantz 1993, Halle 1997) have also often been remarked upon, including by myself, on which more below. Yet since comparable analyses of the Romance verb are available in the DM framework (I am thinking especially of the Italian verb according to Calabrese 2019, cf. also the references 
quoted there), I can't help but feeling that some brief mention of the main points of convergence and divergence between the nanosyntactic and the DM treatment may have greatly clarified the overall discussion.

The main theses of Starke, as explicitly stated in the first few slides, are reported in (1). When it comes to notions of (ir)regularity (1a-b), it seems to me that all morphology that recognises itself in Hallean principles embraces the idea that morphology is a rule governed computational component and therefore (mostly) regular.

(1) a. There is no irregular morphology

b. No irregularity in morphosyntax

c. Principled syntax \& lexicon

A different issue, namely the issue to what extent, if any, morphology can be subsumed under syntax, or rather whether it is in fact syntax, is where the generative field splits, cf. (1c). As is well known, Distributed Morphology (DM) has a somewhat contradictory approach to this. On the one hand, the slogan "syntax all the way down" speaks for itself. On the other hand, DM maintains that there are postsyntactic morphological operations, whose characteristics are such as to prevent their unification with syntax. Most notably, Impoverishment is a deletion operation, but one not working under Recoverability, while Fusion and Fission are essentially remerge rules, which are however prevented from applying in syntax by a number of reasons. Nanosyntax is meant to overcome these internal contradictions and entirely reabsorb morphology under syntax. But it is neither alone nor first in advancing this idea.

Two decades ago, Manzini and Savoia (2002) suggested that phenomena generally deemed to be morphological, such as those involving the internal organisation of the clitic string, are in reality purely syntactic, for instance in the following passage.

"... the theory can derive the relevant properties of clitics in conjunction with a morphological component able to (re)order strings (Bonet 1995, Halle and Marantz 1993...). To the extent that the (re)ordering operations match those of the syntax (Merge and Move), the resulting system is however highly redundant; viceversa to the extent that the two sets of (re)ordering operations do not match, the resulting system is considerably more complex. Therefore we assume that a purely syntactic account is to be preferred for reasons of simplicity of the theory" (Manzini and Savoia 2002: 118).

The passage quoted targets clitic paradigms, but the generalisation to other traditional morphological phenomena is implicit. It is made explicit elsewhere including the title of Manzini and Savoia (2007), "A unification of morphology and syntax", and much subsequent work (Manzini and Savoia 2011, 2018). Writing more or less at the same time as Starke's talk, Collins and Kayne (2020) have a very explicit statement of the overall research program, namely (2), building also on earlier work of Kayne (2010a, 2010b).

Morphology as Syntax (MS) 
Morphological generalizations are accounted for in terms of syntactic operations and principles. There is no morphological component in UG. There are no post-syntactic morphological operations (Collins and Kayne 2020:1).

Now, there are considerable differences between the execution of the program in (2) among the various authors quoted. The interesting question therefore is whether Starke's is better than available alternatives, either in terms of empirical results or in terms of simplicity. This question is best answered by introducing Starke's ideas more in detail. An important point concerns the nature of features, which Starke characterises as in (3a). By unary features he means single valued (positively valued) features. Since these are merged directly into syntax, the syntactic model adopted matters. For Starke this is a model in which each property is unambiguously assigned a position in a functional hierarchy, as in (3b), hence a cartographic model where position and content are unambiguously matched (and universal). ${ }^{1}$

a. Features: unary, Gricean

b. $[\mathrm{f} 3, \mathrm{f} 4, \mathrm{f} 5, \mathrm{f} 6] \quad \rightarrow \quad \ldots[\mathrm{f6} 6 \mathrm{f6}[\mathrm{f5} f 5[\mathrm{f} 4 \mathrm{f} 4[\mathrm{f3} \mathrm{f3} \ldots]]]$

Features are ordered, when possible, by a Boolean logic, so that for instance in (4a) the lowest feature is Person (any person), contained by Participant (i.e. speaker and hearer) and further contained by Speaker. Similarly, in (4b) Plural contains Number (\#). Lexicalisation matches syntactic subtrees to lexical items, as in (5).

$$
\begin{aligned}
& \text { a. }[\text { Spk }[\mathrm{Part}[\pi \\
& \text { b. } \quad[\mathrm{Pl} \quad[\#
\end{aligned}
$$

$\mathrm{XP}$ can lexicalise if the same XP exists in the lexicon

I will comment first on unary feature and then on functional hierarchies of the type in (3b). As discussed by Bafile and Manzini (2019) at least two conceptions of unary features have been developed in phonology in opposition to binary features. One corresponds to underspecification theories, where lack of a feature (in a hierarchy) denotes the complement set to that property. In morphology, this model has been applied to Person by Harley and Ritter (2002). It seems to me, judging from the examples in (4), that Starke's theory is of the underspecification kind. Thus for instance a subtree of the form [Part $[\pi$ is read as Hearer; this means that the absence of the Speaker node implies the property non-Speaker. It follows that the subtree introduces reference to the hearer. In the absence of underspecification the subtree can $[\mathrm{Part}[\pi$ can only be read as referring to Participant, i.e. Hearer or Speaker.

In fact, the tree in (4a) seems a notational variant of Halle's (1997) definition of person in terms of binary features, which I reproduce in (6). Author and Speaker name the same property.

\footnotetext{
1 For reasons of space, Starke's trees are represented here by equivalent labelled brackets expressions.
} 
(6) 1 +author, +participant

2 -author, +participant

3 -author, -participant

* +author, -participant (logically impossible)

(Halle 1997)

Recall that what I am interested in here is the research program unifying morphology and syntax. Now, syntactic nodes have a categorial content, which is unary, but furthermore does not involve underspecification. Therefore, though Starke's trees look very much like syntactic trees, they would seem to be something altogether different. The insistence of Manzini and Savoia (2002, 2007) on lack of underspecification in their model is to be understood in this perspective (e.g. "our theory programmatically avoids reference to what we consider to be theoretically expensive notions of underspecification" (2002: 140)). If categories in syntax are unary features, they are such in the same sense as elements in Government Phonology (Kaye et al. 1985) are. They correspond to positively specified properties which can have a stand-alone interpretation (phonetic, semantic).

Bafile and Manzini (2019) who discuss different feature systems, specifically in relation to Person, propose the unary (no underspecification) features in (7) for the four persons generally recognised to exist. ${ }^{2}$ In (7), both Speaker and Hearer are primitives and the $3^{\text {rd }}$ person is a Demonstrative/Definite. The notion of Participant, though relevant elsewhere (i.e. whenever Person splits occur), is not relevant for the definition of the four persons. ${ }^{3}$

$\begin{array}{ll}\text { 1Excl: } & \text { SPEAKER } \\ \text { 1Incl: } & \text { SPEAKER } \wedge \text { HEARER } \\ \text { 2: } & \text { HEARER } \\ \text { 3: } & \text { D }\end{array}$

(Bafile and Manzini 2019)

Tree formats of the type in (3b) are also worth considering in themselves, leaving aside the type of features that are ordered by them. Their key property is the one-to-one correspondence between the content of any given node and the particular position it is assigned in the tree. In other words, these are cartographic trees. As such, the critical assessment of Chomsky et al. (2019: 251) applies, namely that "the cascades of projections postulated for various areas of clause structure cannot possibly be learned... But attributing complex functional hierarchies to UG raises an evolutionary puzzle: it seems virtually unimaginable that the complex cartographic templates could have evolved as irreducible properties of UG".

Further discussion by Starke illustrates the reordering of morphemes by

$2 \quad 1^{\text {st }}$ person can be either inclusive or exclusive (in the plural), i.e. we can either include or exclude you. Starke has a morphosyntactic tree sufficient to capture 3 persons, as attested in French (English etc.), where 1Excl and 1Incl are systematically syncretic. Yet the issue does arise (in the perspective of a universal morphology) of how 4 persons could in fact be defined.

$3 \pm$ speaker, \pm hearer are the binary features used by Bobaljik (2008); see Bafile and Manzini (2019) for discussion. 
movement. More precisely, so-called roll-up movement, often used within the cartographic model to derive the correct order of constituents, is here used to derive the correct order of morphemes. As Chomsky (2001) discusses in relation to another type of movement, head movement, one should distinguish movement operations that are either interpretively motivated or in any event detectable at the SEM interface from other operations which are labelled movement but which have no interpretive import. Chomskyan movement really modifies the dominance relations of the phrase marker. On the other hand, there is no evidence that head movement or roll-up movement modify anything but precedence relations. In other words, they come at a certain cost.

Against this background, I would like to raise the issue of variation. In cartographic approaches, as just outlined, variation can only result from providing different pronunciations (eventually zero pronunciations) for some portions of the tree - or by (linearly) reordering portions of the tree, under movement driven by language particular needs. Manzini and Savoia (2011) argue that fine grained morphosyntactic variation (so-called microvariation) is hard or impossible to account in these terms, i.e. essentially by assuming that a language particular lexicon is stuck on universal templates. Rather they advocate the "lexicalist" view (also Chomsky's 1995), that different lexicons project slightly different structures:

"...there is a conceptual and grammatical space to be lexicalized and variation results from the distinct partitioning of that space. There is no fixed functional lexicon...

...The view we advocate here is simply that ways of representing the event, such as transitivity or voice... ways of connecting arguments to predicates (or to one another), such as cases..., are to be thought of as part of this general system" (Manzini and Savoia 2011: 4-5).

Under this view, no Uniformity Principle holds to the effect that "the same meaning always maps onto the same syntactic structure" (the formulation is Culicover and Jackendoff's 2005: 6). Convergence of slightly different syntaxes at the SEM interface is a matter of compositional interpretation enriched by context and encyclopedic content.

Only empirical evidence can settle the debate. In this respect, I wonder about very simple matters concerning Starke's analysis, such as the treatment of the $3^{\text {rd }}$ person plural. Eliminating the $3^{\text {rd }}$ plural from the account, as Starke does, means that the /a/ entry can be characterized as singular, Person being irrelevant. ${ }^{4}$ But even leaving aside the $3^{\text {rd }}$ person plural, the question arises of the many person syncretisms possible in Romance, as attested for instance in ItaloRomance varieties (Manzini and Savoia 2005, I: 219-267). Most Romance literature that I am familiar with tackles nominal and pronominal paradigms rather than verbal ones. Calabrese (2011) provides an exhaustive account of syncretisms in the subject clitic paradigms of North Italian varieties, within a DM framework. Manzini and Savoia (2020) take up the matter from the different point of view of partial null subject patterns, keeping in mind that patterns of possible syncretisms

$4 \quad$ Incidentally, I wonder why the relevant French forms aren't simply identified with the bare stem. 
overlap with patterns of possible pro drop. An extension to verbal paradigms is not available.

In short, Starke's account of the French verbal paradigm represents a thought-provoking contribution to the analysis of Romance agreement inflections and more generally verbal inflections. My points nevertheless stand, that testing against variation data, and crucially comparison with other formal treatments, may prove crucial for an assessment of the actual working of the system.

\section{References}

Bafile, Laura \& M. Rita Manzini, 2019. From Phonological Rules to the Person Case Constraint. Monovalent vs. Bivalent Features in Grammar. Quaderni di Linguistica e Studi Orientali (QULSO) 5: 9-53. https://doi.org/10.13128/QULSO-2421-7220-25961

Bobaljik, Jonathan. 2008. Missing Persons: A Case Study in Morphological Universals. The Linguistic Review 25: 203-230.

https://doi.org/10.1515/TLIR.2008.005

Bonet, Eulalia. 1995. Feature structure of Romance clitics. Natural Language and Linguistic Theory 13: 607-647. DOI: https://doi.org/10.1007/BF00992853

Calabrese, Andrea. 2011. Investigations on Markedeness, Syncretism and Zero Exponence in Morphology. Morphology 21.2: 283-325.

https://doi.org/10.1007/s11525-010-9169-y

Calabrese, Andrea. 2019. Morpho-Phonological Investigations:A Theory of PF. From Syntax to Phonology in Sanskrit and Italian Verbal Systems. Ms., UConn, Storrs, CT.

Retrieved on $9 / 7 / 2021$ at https://drive.google.com/drive/folders/1cHAra3YiAsUR9marF5wquJN0NUcPQ0 $\underline{\mathrm{YT}}$

Chomsky Noam. 1995. The Minimalist Program, Cambridge Mass: The MIT Press.

Chomsky, Noam. 2001. Derivation by phase. In: Michael Kenstowicz (ed.), Ken Hale: A life in language, 1-52. Cambridge Mass.: The MIT Press.

Chomsky, Noam, Gallego, Ángel \& Dennis Ott. 2019. Generative Grammar and the Faculty of Language: Insights, Questions, and Challenges. In Ángel Gallego \& Dennis Ott (eds). Generative Syntax: Questions, Crossroads, and Challenges. Special issue of Catalan Journal of Linguistics.

https://doi.org/10.5565/rev/catj1.288

Collins, Chris \& Richard Kayne. 2020. Towards a Theory of Morphology as Syntax. Ms., NYU. 
Culicover, Peter \& Ray Jackendoff. 2005. Simpler syntax. Oxford: Oxford University Press.

Halle, Morris. 1997. Distributed Morphology: Impoverishment and Fission. In Benjamin Bruening, Yoonjung Kang \& Martha McGinnis (eds.) PF: Papers at the Interface, 425-449. Cambridge MA: MIT Working Papers in Linguistics.

Halle, Morris \& Alec Marantz. 1993. Distributed morphology and the pieces of inflection. In Ken Hale and Samuel J. Keyser (eds.), The view from Building 20, 111-176. Cambridge MA: The MIT Press.

Harley, Heidi \& Elisabeth Ritter. 2002. Person and Number in Pronouns: A Feature-Geometric Analysis. Language 78: 482-526.

https://doi.org.10.1353/lan.2002.0158

Jespersen, Otto. 2013 [1924]. The philosophy of Grammar. London: Routledge.

Kaye, Jonathan, Lowenstamm, Jean \& Jean-Roger Vergnaud. 1985. The Internal Structure of Phonological Elements: a Theory of Charm and Government. Phonology 2: 305-328.

https://doi.org/10.1017/S0952675700000476

Kayne, Richard. 2010a. Comparisons and Contrasts. New York: Oxford University Press.

Kayne, Richard. 2010b. Toward a syntactic reinterpretation of Harris and Halle (2005). In R. Bok-Bennema, B. Kampers-Manhe \& B. Hollebrandse (eds.), Romance Languages and Linguistic Theory 2008, Selected papers from 'Going Romance' Groningen 2008, 145-170. Amsterdam: John Benjamins. https://doi.org/10.1075/rllt.2.09kay

Manzini, M. Rita \& Leonardo M. Savoia. 2002. Clitics: Lexicalization patterns of the so-called 3rd person clitic. Catalan Journal of Linguistics 1: 117-55. https://raco.cat/index.php/CatalanJournal/article/view/308953

Manzini, M. Rita \& Leonardo M. Savoia. 2005. I dialetti italiani e romanci. Morfosintassi generativa. Vol. I-III. Alessandria: Edizioni dell’Orso.

Manzini, M. Rita \& Leonardo M. Savoia. 2007. A unification of morphology and syntax. Studies in Romance and Albanian varieties. London: Routledge.

Manzini, M. Rita \& Leonardo M. Savoia. 2011. Grammatical Categories. Cambridge: Cambridge University Press.

Manzini M. Rita \& Leonardo M. Savoia. 2018. The Morphosyntax of Albanian and Aromanian Varieties. Berlin: De Gruyter Mouton. 
Manzini M. Rita, and Leonardo M. Savoia. 2020. Person splits in Romance: Implications for parameter theory. In András Bárány, Theresa Biberauer, Jamie Douglas \& Sten Vikner (eds.), Syntactic architecture and its consequences II, 403-434. Berlin: Language Science Press.

https://doi.org/10.5281/zenodo.4280663 